\title{
In vivo gene transfer of endothelial nitric oxide synthase decreases portal pressure in anaesthetised carbon tetrachloride cirrhotic rats
}

\author{
M Van de Casteele, A Omasta, S Janssens, T Roskams, V Desmet, F Nevens, J Fevery
}

Gut 2002;51:440-445

See end of article for authors' affiliations

Correspondence to: Dr J Fevery, Division of Liver and Pancreatic Diseases, University Hospital Gasthuisberg, B-3000 Leuven, Belgium; Johan.Fevery@ uz.kuleuven.ac.be

Accepted for publication 18 December 2001

\begin{abstract}
Background: Portal hypertension in cirrhosis results from enhanced intrahepatic resistance to an augmented inflow. The former is partly due to an imbalance between intrahepatic vasoconstriction and vasodilatation. Enhanced endothelin-1 and decreased activity of hepatic constitutive endothelial nitric oxide synthase (NOS 3) was reported in carbon tetrachloride $\left(\mathrm{CCl}_{4}\right)$ cirrhotic rat liver.

Aims: To study whether an increase in hepatic NOS 3 could be obtained in the $\mathrm{CCl}_{4}$ cirrhotic rat liver by in vivo cDNA transfer and to investigate a possible effect on portal pressure.

Methods: Hepatic NOS 3 immunohistochemistry and western blotting were used to measure the amount of NOS 3 protein. Recombinant adenovirus, carrying cDNA encoding human NOS 3, was injected into the portal vein of $\mathrm{CCl}_{4}$ cirrhotic rats. Cirrhotic controls received carrier buffer, naked adenovirus, or adenovirus carrying the lac $\mathrm{Z}$ gene.

Results: NOS 3 immunoreactivity and amount of protein (western blotting) were significantly decreased in $\mathrm{CCl}_{4}$ cirrhotic livers. Following cDNA transfer, NOS 3 expression and the amount of protein were partially restored. Portal pressure was $11.4(1.6) \mathrm{mm} \mathrm{Hg}$ in untreated cirrhotic $(\mathrm{n}=9)$ and $11.8(0.6)$ in lac $Z$ transfected $(n=4)$ cirrhotic rats but was reduced to 7.8 (1.0) $\mathrm{mm} \mathrm{Hg}(\mathrm{n}=9)$ five days after NOS 3 cDNA transfer. No changes were observed in systemic haemodynamics, in liver tests or urinary nitrates, or in NOS 3 expression in lung or kidney, indicating a highly selective transfer.

Conclusions: NOS 3 cDNA transfer to cirrhotic rat liver is feasible and the increase in hepatic NOS 3 leads to a marked decrease in portal hypertension without systemic effects. These data indicate a major haemodynamic role of intrahepatic NOS 3 in the pathogenesis of portal hypertension in $\mathrm{CCl}_{4}$ cirrhosis.
\end{abstract}

P ortal hypertension is a major complication of cirrhosis. The elevated portal pressure results from enhanced sinusoidal resistance to the augmented influx of portal venous blood. ${ }^{1}$ The latter is secondary to extrahepatic arteriolar vasodilatation characterised by a diminished reactivity to endogenous vasoconstrictors, including noradrenaline and angiotensin $\mathrm{II}^{2}$ presumably as a result of the enhanced presence of vasodilator substances. ${ }^{134}$ Recent data point to an important role of nitric oxide (NO), produced in the endothelium of the aorta and mesenteric arteries by the constitutive endothelial nitric oxide synthase (NOS 3 ) in the pathogenesis of this peripheral vasodilatation. ${ }^{4-6}$ Enhanced hepatic vascular resistance due to fibrotic tissue seems poorly susceptible to therapeutic intervention. However, studies in the isolated perfused cirrhotic rat liver as well as in cirrhotic patients demonstrated that enhanced intrahepatic vascular resistance is, at least in part, provoked by contractile elements ${ }^{7-14}$ and as such amendable. Activated hepatic stellate cells seem especially involved in this process as they transform into myofibroblasts that can constrict the sinusoids. ${ }^{14}{ }^{15}$ Endothelin-1 and NO are considered the most important vasoconstrictor and vasodilator agents, respectively, that act on stellate cells. ${ }^{10-15}$ Normal portal vein pressure seems to result from a balance between intrahepatic NO production by endothelial cells ${ }^{141617}$ and vasoconstrictor agents such as endothelin- $1 .{ }^{17}{ }^{18}$ In the carbon tetrachloride $\left(\mathrm{CCl}_{4}\right)$ cirrhotic rat model, preliminary results have shown that NOS 3 immunoreactivity as well as liver NOS activity was reduced. ${ }^{19} 20$ Furthermore, endothelial cells isolated from $\mathrm{CCl}_{4}$ cirrhotic livers were shown to have reduced NOS activity. ${ }^{21}{ }^{22}$ The enhanced portal vein pressure in cirrhosis could thus result from insufficient production of NO to counteract the enhanced endothelin- $1 .{ }^{14}$ If this is correct, an increase in locally produced NO could lead to a reduction in portal hypertension.

To study these pathophysiological events, we measured hepatic NOS 3 in $\mathrm{CCl}_{4}$ cirrhotic rat liver and investigated whether NOS 3 could be enhanced in the liver by in vivo cDNA transfer and if this cDNA transfer had an effect on portal pressure. $^{19}$

\section{MATERIALS AND METHODS \\ $\mathrm{CCL}_{4}$ cirrhosis}

Cirrhosis was induced by $\mathrm{CCl}_{4}$ given by gavage over 12 weeks to inbred male Wistar rats of 200-250 g (Animal House, University of Leuven, Belgium) receiving phenobarbital in their drinking water, as outlined previously. ${ }^{23}$ Treatment of the animals was approved by the local committee for animal experimentation of the Catholic University of Leuven

\section{In vivo cDNA transfection in cirrhotic rats}

Cirrhotic rats were randomly assigned to receive, by intraportal injection, recombinant El deleted adenovirus serotype 5 carrying human NOS 3 cDNA (Ad5NOS3) $(n=9)$. Generation by homologous recombination of this adenovirus, its purification, as well as the feasibility of in vivo cDNA transfer have been reported previously. ${ }^{24-26}$

Other cirrhotic rats served as controls and received:

Abbreviations: $A d 5$, recombinant adenovirus serotype $5 ; \beta$-Gal, $\beta$-galactosidase; $\mathrm{CCl}_{4}$, carbon tetrachloride; $\mathrm{NO}$, nitric oxide; $\mathrm{NOS} 3$, constitutive endothelial nitric oxide synthase (NOS isoform 3). 
(a) carrier buffer (placebo): $400 \mu 100 \mathrm{mM}$ Tris $\mathrm{HCl} \mathrm{pH} 7.4$ $(\mathrm{n}=9)$;

(b) recombinant El deleted adenovirus serotype 5 carrying the cDNA of the lac $\mathrm{Z}$ gene (Ad5 $\beta \mathrm{Gal}$ ) encoding an Escherichia coli $\beta$-galactosidase $(\beta$-Gal) $(n=4)$. This reporter enzyme allows assessment of the distribution of cDNA transfer and the histological effect of adenoviral transfection;

(c) recombinant El deleted adenovirus serotype 5 without added cDNA (so-called empty virus Ad5RR) $(n=3)$.

Normal rats $(n=9)$ served as another control group; five underwent Ad5NOS3 cDNA transfer and the other four received empty virus Ad5RR.

\section{Technique of intraportal injection}

$\mathrm{CCl}_{4}$ cirrhotic rats were kept under pentobarbital anaesthesia $(30 \mathrm{mg} / \mathrm{kg})$; the portal vein was temporarily clamped with a non-traumatic microsurgical clamp as close as possible to the liver hilum. A fine needle (26 gauge) was inserted in the portal vein between the clamp and the liver. The portal circulation was first rinsed with $1 \mathrm{ml}$ of $100 \mathrm{mM}$ Tris $\mathrm{HCl} \mathrm{pH} \mathrm{7.4.} \mathrm{Then,}$ $400 \mu \mathrm{l}$ of Tris $\mathrm{HCl}$ buffer $\mathrm{pH} 7.4$ (placebo) or $400 \mu \mathrm{l}$ of $5 \times 10^{9}$ $\mathrm{pfu} / \mathrm{ml}$ Ad5RR (empty virus), Ad5ßGal, or Ad5NOS3 was slowly injected into the portal vein. This was followed by injection of $100 \mu \mathrm{l}$ of Tris $\mathrm{HCl}$ buffer. The clamp was kept on the portal vein for 30 minutes to prolong adenovirussinusoidal cell contact. The abdomen was closed and the animal allowed to recover from anaesthesia.

In preliminary experiments, the optimal dose of recombinant adenovirus carrying the NOS 3 cDNA had been evaluated using concentrations ranging from $5 \times 10^{6} \mathrm{pfu} \mathrm{Ad} 5 / \mathrm{ml}$ to $5 \times 10^{11} \mathrm{pfu} \mathrm{Ad} 5 / \mathrm{ml}$. Low adenovirus concentrations did not lead to an increase in NOS 3 expression whereas the highest concentration provoked a mild granulomatous hepatitis (data not shown). Therefore, we used 100-fold lower concentration $\left(5 \times 10^{9} \mathrm{pfu} / \mathrm{ml}\right)$ of adenovirus for further experiments.

\section{Haemodynamic and biochemical measurements}

Haemodynamic measurements were carried out in a nonblinded way on day 0 and day 5 in normal rats, transfected with $\operatorname{Ad5NOS3}(n=5)$ or empty virus $(n=4)$, and on day 5 in placebo cirrhotic rats $(n=9)$, in Ad5 $\beta$ Gal transfected cirrhotic rats $(n=4)$, and in Ad5NOS3 transfected cirrhotic rats $(n=9)$. Twenty four hour urine was collected on day 4 for measurement of urinary creatinine, sodium, and nitrates. The jugular vein, carotid artery, and a branch of the mesenteric vein or portal vein were cannulated with polyethylene 10 catheters under mild pentobarbital anaesthesia. All pressures were obtained by a pressure transducer (Servocorder SR 6255n; Watanabe, Japan). Later, animals were killed with an overdose of sodium pentobarbital and the liver, kidneys, and lungs were removed for histology. Blood was taken from the abdominal aorta. Biochemical analysis was carried out by automated laboratory procedures (BM Hitachi 911; Boehringer Mannheim, Germany). Serum bile acids and urinary nitrate concentrations were measured with photometric colour tests (Merckotest Bile Acids and Spectroquant Nitrate, respectively; Merck, Darmstadt, Germany).

\section{Immunohistochemistry}

Liver, kidney, and lung specimens from all cirrhotic rats and from 10 healthy control rats of the same age were studied. Specimens were fixed in B5-fixative for light microscopic examination. Random biopsies were snap frozen in liquid nitrogen cooled isopentane, stored at $-70^{\circ} \mathrm{C}$, and used for immunohistochemistry.

\section{NO synthase 3 immunohistochemistry}

A three step indirect immunoperoxidase method was used on frozen sections. A mouse monoclonal antibody specific for

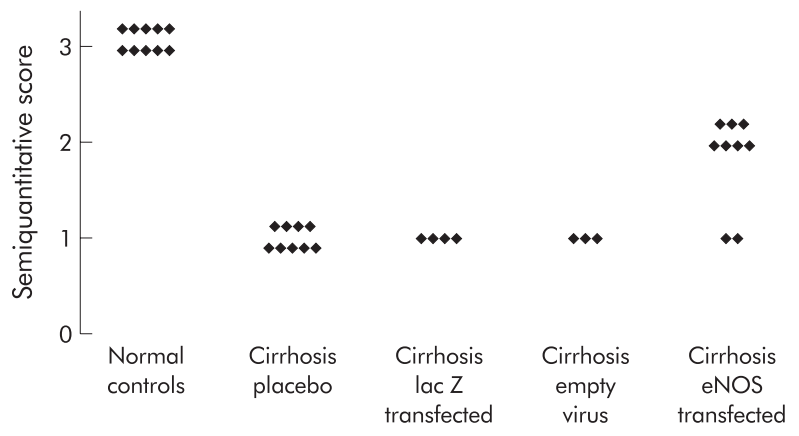

Figure 1 Mean score for constitutive endothelial nitric oxide synthase (eNOS) immunoreactivity of sinusoidal endothelial cells obtained from 10 different high power fields is given semiquantitatively as no reactivity $(0)$, weak reactivity (1), moderately strong (2), and strong reactivity (3).

human NOS 3 was obtained from Transduction Labs (Lexington, Kentucky, USA) and used at a dilution of $1 / 200$. Incubation of the primary antibody was followed by peroxidase conjugated rabbit antimouse and peroxidase conjugated swine antirabbit immunoglobulins. All secondary and tertiary antisera were from Dakopatts (Copenhagen, Denmark) and diluted in phosphate buffered saline, $\mathrm{pH}$ 7.2, containing $10 \%$ normal human serum. All incubations were carried out for 30 minutes at room temperature and followed by a wash in three changes of phosphate buffered saline, $\mathrm{pH} 7.2$, for 15 minutes. The reaction product was revealed by 3-amino-9ethylcarbazole and hydrogen peroxide. We performed counterstaining with Mayer's haematoxylin. Negative controls consisted of replacement of the primary antibody by non-immune mouse ascites (Cappel Labs, Cochranville, Pennsylvania, USA). NOS 3 immunoreactivity in liver endothelial cells was semiquantitatively scored as no reactivity $(0)$, weak reactivity (1), moderately strong reactivity (2), and strong reactivity (3) (fig 1). For semiquantitative immunohistochemical scoring of NOS 3, 10 different high power fields were viewed each time and were scored blindly and independently by two pathologists and a mean taken as the final score.

\section{Galactosidase enzyme histochemistry}

For the $\beta$-D-galactosidase reaction, cryostat sections were incubated for 12 hours with an incubation medium consisting of $3 \mathrm{mg}$ of 5-bromo-4-chloro-3-indoxyl- $\beta$-D-galactopyranoside (Sigma, St Louis, Missouri, USA), $0.3 \mathrm{ml} N, N$ dimethylformamide (Merck, Darmstadt, Germany), $7 \mathrm{ml}$ of $0.1 \mathrm{M}$ citric acid phosphate, $\mathrm{pH} 5$, and $0.5 \mathrm{ml}$ of $1.65 \%$ $\mathrm{K}$-ferrocyanide, followed by a wash in distilled water and post-fixation in $4 \%$ paraformaldehyde. The slides were counterstained with Nuclear Fast Red.

\section{Immunoblotting (western blotting)}

Samples of fresh liver tissue were homogenised at a concentration of $0.25 \mathrm{~g}$ wet weight of liver/ $\mathrm{ml}$ in Chaps buffer, containing $40 \%$ glycerol; $0.2 \mathrm{M} \mathrm{K}_{2} \mathrm{PO}_{4} \cdot \mathrm{H}_{2} \mathrm{O}$ pH 7.2 and $20 \mathrm{mM}$ Chaps (Sigma). Protein concentration was quantitated according to Bradford. ${ }^{27}$ Equal amounts of protein $(30 \mu \mathrm{g})$ from each sample were separated by $7.5 \%$ sodium dodecyl sulphate-polyacrylamide gel electrophoresis. ${ }^{28}$ The separated proteins underwent electrophoretic transfer onto nitrocellulose Protran membranes (Schleicher and Schuell, Dassel, Germany) for 1.5 hours. The proteins on the membrane were blocked in blotto-Tween solution (5\% skimmed milk; $0.05 \%$ Tween 20 ) at $4^{\circ} \mathrm{C}$ overnight. Incubation with primary antibodies (mouse monoclonal anti-NOS 3 IgG 1:1000; Transduction Labs) was performed at room temperature for two hours, followed by washing with phosphate buffered saline-Tween buffer (137 mM NaCl; $38 \mathrm{mM} \mathrm{Na} \mathrm{HPO}_{4} .12 \mathrm{H}_{2} \mathrm{O} ; 1.8 \mathrm{mM}$ 

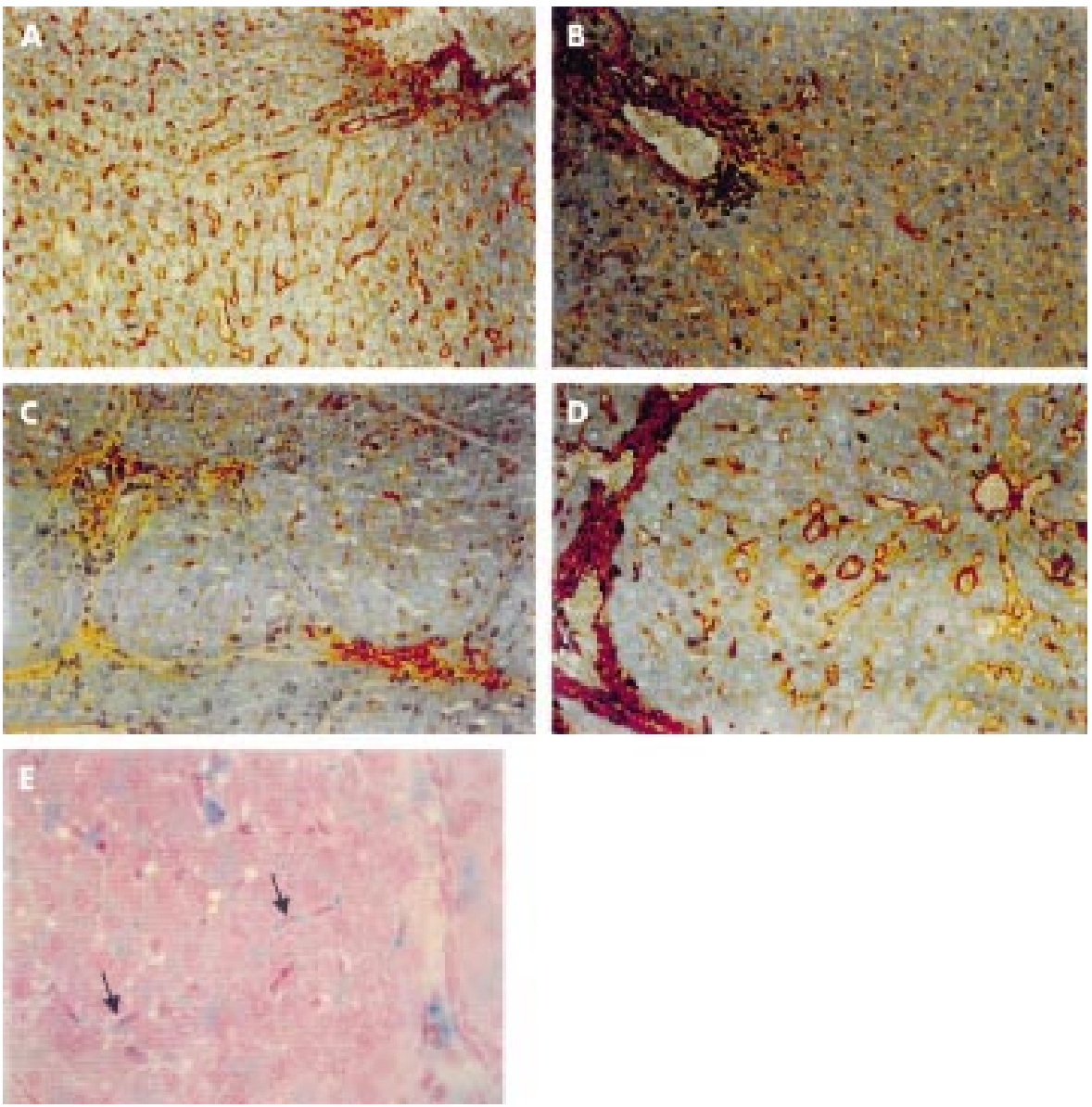

Figure 2 Constitutive endothelial nitric oxide synthase (NOS 3) immunostaining in rat liver tissue. Peroxidase immunohistochemical stain, counterstained with Mayer's haematoxylin (x250). (A) Normal liver: NOS 3 is strongly expressed in the endothelial cells of blood vessels and in sinusoidal endothelial cells. (B) Cirrhotic rats treated with placebo: NOS 3 is markedly reduced in sinusoidal endothelial cells but not in vascular endothelium of the portal tracts. (C) Cirrhotic rats five days after Ad5 3 Gal transfection: NOS 3 immunoreactivity is similar as that of placebo treated cirrhotic rats. (D) Cirrhotic rats five days after AdNOS3 transfection: NOS 3 expression is enhanced in sinusoidal lining cells compared with that in placebo treated livers. (E) Enzymatic staining for galactosidase in a lac $Z$ transfected cirrhotic rat $(\times 250)$.

$\mathrm{NaH}_{2} \mathrm{PO}_{4} .2 \mathrm{H}_{2} \mathrm{O} ; 0.05 \%$ Tween 20) and incubation with a secondary peroxidase conjugated rabbit antimouse Ig 1:1000 (Dako, Glostrup, Denmark), and visualised using enhanced chemiluminescence detection (ECL, Amersham, Rainham, UK).

\section{Statistics}

All data are expressed as mean (SEM). Results from transfected and non-transfected rats were compared using an unpaired Student's $t$ test.

\section{RESULTS}

\section{NOS 3 histochemistry}

The mean semiquantitative scores, obtained by two independent pathologists unaware of the treatment of the rats, are given in fig 1 . Livers of normal rats (fig 2) demonstrated NOS 3 immunoreactivity in arterial and venous endothelium in the portal tracts. Bile duct epithelium was negative. In liver parenchyma, NOS 3 immunoreactivity was observed in sinusoidal and hepatic vein endothelium but hepatocytes were negative. In specimens of $\mathrm{CCl}_{4}$ cirrhotic rats treated with buffer (placebo group), the intensity of the NOS 3 immunoreactivity in sinusoidal endothelial cells was markedly reduced (fig 2) compared with normal livers but not with that of the vascular endothelium in the portal tracts. Livers of cirrhotic rats transfected with Ad5 $\beta$ Gal (fig 2) or with empty virus had a similar intensity of sinusoidal NOS 3 immunoreactivity as placebo rats. $\beta$-Gal staining confirmed intrahepatic lac $\mathrm{Z}$ transfection in sinusoidal lining cells and in rare hepatocytes (fig 2). Cirrhotic rats transfected with Ad5NOS3 showed enhanced NOS 3 immunoreactivity in the sinusoidal lining cells (fig 2) compared with placebo treated or lac $\mathrm{Z}$ transfected animals but NOS 3 expression was still below that of non-cirrhotic rats. NOS 3 staining in endothelial cells in the lungs and kidneys was not different in the various groups (data not shown).

\section{Immunoblotting (western blots)}

The amount of immunoreactive hepatic NOS 3 protein identified in western blots was always lower in $\mathrm{CCl}_{4}$ cirrhotic than in normal control rats (fig 3). Livers from seven $\mathrm{CCl}_{4}$ rats yielded values obtained by densitometry of 66.7 (6.4)\% of those of seven healthy controls. The amounts of NOS 3 protein were increased following transfection with Ad5NOS3 (93.7 (6.6)\%; $\mathrm{n}=5$ ) but not significantly following injection of Ad5RR (72 $(5.2) \% ; n=5)$.

\section{Haemodynamic and biochemical data following NOS 3 cDNA transfer}

On day 5, portal vein pressure was $6.4(0.5) \mathrm{mm} \mathrm{Hg}$ in normal rats transfected with empty virus $(n=4)$ and significantly lower in AdNOS3 transfected animals (3.9 (0.3) $\mathrm{mm} \mathrm{Hg}$; $=5$ ) $(\mathrm{p}=0.04)$. In cirrhotic rats, portal vein pressure was 11.4 (1.6) $\mathrm{mm} \mathrm{Hg}$ in placebo treated rats $(\mathrm{n}=9)$ and only $7.8(1.0) \mathrm{mm}$ $\mathrm{Hg}$ in Ad5NOS3 transfected rats $(\mathrm{n}=9)(\mathrm{p}=0.04)$ (fig 4). Transfection with Ad5 $\beta$ Gal did not have an effect on portal pressure as it was $11.8(0.6) \mathrm{mm} \mathrm{Hg}(\mathrm{n}=4)$ in this group. 


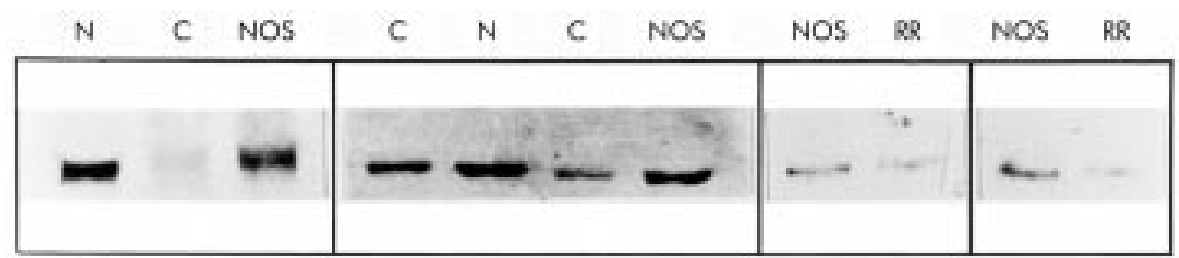

Figure 3 Four separate representative western immunoblots of constitutive endothelial nitric oxide synthase (NOS 3) are given as examples, comparing normal (N) (lanes 1 and 5) with carbon tetrachloride cirrhotic non-transfected rats (C) (lanes 2, 4, and 6), animals transfected with Ad5NOS3 (NOS) (lanes 3, 7, 8, and 10), and those who received the empty virus Ad5RR (RR) (lanes 9 and 11).

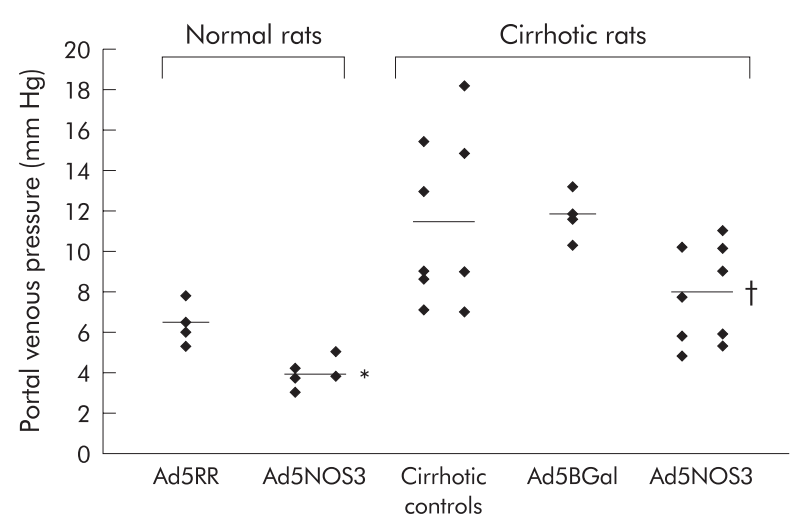

Figure 4 Portal vein pressures (with mean values), obtained on day 5 following transfection with Ad5NOS3 or Ad5RR (empty virus) in normal rats, and following placebo injection or transfection with Ad5NOS3 or Ad $3 \mathrm{Gal}$ in cirrhotic rats. Ad5RR, empty adenovirus; Ad5 $\beta$ Gal, adenovirus encoding lac $Z$ reporter gene; controls, injection of placebo; Ad5NOS3, adenovirus encoding NOS 3 cDNA. * $p=0.04$ compared with normal rats treated with Ad5RR; $t p=0.04$ compared with cirrhotic placebo treated rats.

Arterial and central venous pressures remained unaltered by Ad5NOS3 gene transfer and were 101 (6) and 102 (16) $\mathrm{mm} \mathrm{Hg}$ and $-1.5(2.0)$ and $-1.6(0.7) \mathrm{mm} \mathrm{Hg}$ in the nine Ad5NOS3 transfected and nine placebo treated cirrhotic rats, respectively. The 24 hour urinary nitrate excretion was not different in placebo versus Ad5NOS3 transfected rats under similar food and fluid intake (table 1). Serum electrolytes, liver tests, and urinary nitrates did not differ (table 1).

\section{DISCUSSION}

Sinusoidal hypertension in cirrhosis results from enhanced resistance due to hepatocytic and fibrotic alterations ${ }^{13}$ and to active vasoconstriction ${ }^{10-14}$ counterbalanced by vasodilating substances. In normal and cirrhotic liver, both endothelin-l and NO, major vasoconstrictor and vasodilator substances, respectively, were shown to be important determinants of portal pressure. ${ }^{11-18} 2930$ Reduced production of NO by endothelial cells from the $\mathrm{CCl}_{4}$ cirrhotic rat liver may be an important factor causing enhanced sinusoidal vasoconstriction. ${ }^{19-22}$ Under normal conditions, as well as in end stage $\mathrm{CCl}_{4}$ cirrhosis, constitutional endothelial NOS 3, and not the inducible NOS isoform, is the major intrahepatic enzyme catalysing NO formation..$^{162}{ }^{20}$ The activity of hepatic NOS has been reported to be decreased in $\mathrm{CCl}_{4}$ cirrhotic rat livers ${ }^{20-22}$ and often in human end stage cirrhosis. ${ }^{31}$ Decreased NOS activity can be due to decreased amounts of protein and/or decreased enzyme activity. Several factors may influence the activity of hepatic NOS 3: the availability of the substrate L-arginine ${ }^{32}$ or possible recycling of L-citrulline back to L-arginine in endothelial cells, $^{33}$ or inhibitory actions of caveolin-1 on NOS 3 activity. ${ }^{34-36}$

The present study showed that NOS 3 immunostaining was reduced in liver sinusoids of $\mathrm{CCl}_{4}$ cirrhotic rats to a similar extent as that observed in human viral and alcoholic cirrhosis. $^{37}$ NOS 3 immunostaining was homogeneous throughout the liver both in normal and $\mathrm{CCl}_{4}$ cirrhotic rat livers in contrast with the situation in human cirrhotic livers. ${ }^{37}$ Our semiquantitative scoring system of NOS 3, counting 10 different high power fields, minimised the impact of eventual immunohistochemical heterogeneity and demonstrated a clear cut decrease in $\mathrm{CCl}_{4}$ cirrhotic livers (figs 1,2). This scoring allowed detection of enhanced NOS 3 expression, after NOS 3 cDNA transfection into $\mathrm{CCl}_{4}$ cirrhotic rat livers with adenovirus as carrier. These results were corroborated by western blot analysis (fig 3), demonstrating a significant decrease in NOS 3 protein in $\mathrm{CCl}_{4}$ cirrhotic rats, which was increased by gene transfer. The lower NOS 3 protein values of $\mathrm{CCl}_{4}$ cirrhotic rats differ from those reported by Shah and

Table 1 Biochemical data (mean (SEM)) comparing placebo treated and Ad5NOS3 transfected carbon tetrachloride cirrhotic rats on day $4(\mathrm{~d} 4)$ or day 5 (d5)

\begin{tabular}{|c|c|c|}
\hline & Placebo $(n=9)$ & Ad5NOS3 transfected $(n=9)$ \\
\hline Food intake d4 (g/24 h) & (1) & (1) \\
\hline Fluid intake $\mathrm{d} 4(\mathrm{ml} / 24 \mathrm{~h})$ & 31 & 34 \\
\hline Diuresis $\mathrm{d} 4(\mathrm{ml} / 24 \mathrm{~h})$ & $13 \quad$ (1) & $13 \quad(2)$ \\
\hline Natriuresis d4 (mmol/ $24 \mathrm{~h})$ & $1.3(0.1)$ & $1.1(0.1)$ \\
\hline Urinary nitrates $\mathrm{d} 4(\mathrm{mmol} / 24 \mathrm{~h})$ & $48 \quad$ (6) & $44 \quad(16)$ \\
\hline Creatinine clearance $\mathrm{d} 4(\mathrm{ml} / \mathrm{min})$ & $1.34(0.11)$ & $1.21(0.10)$ \\
\hline Liver weight d5 (g) & $14.8 \quad(0.5)$ & $15.5 \quad(0.8)$ \\
\hline Spleen weight d5 (g) & $1.5(0.3)$ & $1.4(0.3)$ \\
\hline \multicolumn{3}{|l|}{ Serum values on $\mathrm{d} 5$} \\
\hline $\mathrm{Na}$ (NV 132-145 mmol/l) & 137 & 152 \\
\hline AP (NV 90-260 U/I) & 251 & 368 \\
\hline AST (NV 5-37 U/I) & 125 & 168 \\
\hline ALT (NV 5-40 U/I) & $76 \quad(24)$ & $74 \quad(17)$ \\
\hline Bilirubin $(\mathrm{mg} / \mathrm{dl})$ & $0.43(0.12)$ & $0.51(0.10)$ \\
\hline Bile acids ( $\mu \mathrm{mol} / \mathrm{l})$ & 160 & 155 \\
\hline
\end{tabular}

NV, normal values

$A P$, alkaline phosphatase; AST, aspartate aminotransferase; ALT, alanine aminotransferase. 
colleagues $^{36}$ but are comparable with those obtained elsewhere ( $58(6) \%$ of normal values; $\mathrm{n}=40$ ) (personal communication, Van de Casteele and Reichen). The exact reason for this difference is not clear but may be due to a different immunoblotting procedure as these investigators used an immunoprecipitation step and resuspension prior to protein electrophoresis, ${ }^{36}$ or possibly to differences in the severity of cirrhosis.

Importantly, the increase in hepatic NOS 3 following transfection was paralleled by a $32-38 \%$ reduction in portal vein pressure both in normal and cirrhotic rats compared with placebo treated, Ad5RR transfected, or Ad5 $\beta$ Gal transfected rats (fig 4). Our results are in agreement with the recent studies by Yu and colleagues ${ }^{38}$ who observed a decrease in portal pressure and portal resistance following adenoviral mediated gene transfer of neuronal NOS 1 into both bile duct ligated and $\mathrm{CCl}_{4}$ cirrhotic rats, and with that of Shah and colleagues ${ }^{39}$ transfecting eNos. As they injected the gene via the femoral vein, mainly hepatocytes were transfected in addition to sinusoid lining cells. By using the portal route and by injecting a lower amount of adenovirus $\left(10^{9} \mathrm{pfu} / \mathrm{ml}\right.$ in our study $v 10^{11}$ in the studies of Yu and colleagues ${ }^{38}$ and Shah and colleagues ${ }^{39}$ ) we tried to avoid transfection of hepatocytes as NOS in hepatocytes may interact with sole activation of sinusoid lining cells. In both control groups, haemodynamic data remained unaltered. Arguments in favour of organ selectivity of intraportal NOS 3 cDNA transfer to the liver were obtained from the lack of alterations in 24 hour nitrate excretion in urine (table 1), from the unchanged arterial and central venous pressures, and from the unaltered NOS 3 immunoreactivity in the kidneys and lungs of transfected rats. In both Ad5 $\beta \mathrm{Gal}$ and Ad5NOS3 transfected groups, it was shown that intraportal adenovirus injection at the present dose did not provoke inflammation. Admittedly, the haemodynamic measurements were carried out under general anaesthesia with barbiturates but our previous studies did not detect a major effect of this type of anaesthesia on portal pressure, ${ }^{40}$ and the conditions were identical for transfected and non-transfected animals. We only measured portal vein pressure; a possible effect of NOS 3 cDNA transfer on effective total hepatic blood flow in $\mathrm{CCl}_{4}$ cirrhotic rats has still to be investigated. The decrease of $38 \%$ induced by Ad5NOS3 transfection in our normal rats confirms that NOS 3 plays a role in maintaining normal portal vein pressure, ${ }^{17}$ possibly in part by counterbalancing the effect of endothelin-1 as administration of bosentan slightly decreased portal pressure. ${ }^{18}$

In recent years, adenovirus mediated gene transfer has been studied as a new strategy to treat hereditary infectious and malignant diseases of the liver. ${ }^{41}{ }^{42}$ The in vivo susceptibility of normal rat hepatocytes for adenovirus mediated gene transfer is high following intravenously administered adenoviral vectors, ${ }^{43}{ }^{44}$ but liver tropism may be different in cirrhotic livers as fibrous septa and loss of endothelial fenestrae could hamper adenovirus attachment to hepatocytes but favour transmission to sinusoidal cells. ${ }^{38} 44$

Transfection with adenovirus will presumably exert only a temporary effect as the lifespan of the transgene is transient and because vasoconstrictor agents, such as endothelin-l, could arise as part of a counterregulatory mechanism. Such an increase in the production of endothelin is supported by early enhancement of preproendothelin mRNA observed in endothelial cells and more so in stellate cells following bile duct ligation. ${ }^{45}$ Further studies are thus necessary to obtain prolongation of the enhancement of NOS 3 protein and activity.

In isolated normal ${ }^{46}$ and $\mathrm{CCl}_{4}$ cirrhotic rat livers, ${ }^{78}$ injection of NO donating drugs such as nitroprusside or glyceryl trinitrate counteract noradrenaline induced vasoconstriction and diminish portal pressure but in the in vivo situation the effect on the systemic arterial system prevails, and even intraportal injection leads primarily to arterial hypotension. ${ }^{47}$ This condition differs from the one whereby NO is locally produced by endothelial cells under the action of NOS 3.
In conclusion, the present study provides further evidence for an active component in the pathogenesis of the increased intrahepatic vascular tone in cirrhosis. $\mathrm{CCl}_{4}$ rat livers have a decrease in NOS 3 protein, and intraportal cDNA transfer of NOS 3 using adenovirus as vector was feasible in vivo in these rats. The decrease in portal pressure observed following NOS 3 transfection indicates a major haemodynamic role for NOS 3 in $\mathrm{CCl}_{4}$ cirrhosis.

\section{ACKNOWLEDGEMENTS}

The studies were supported by a grant from the Fund for Scientific Research (FWO No 6.0111.98-F Nevens) and by a fellowship from the committee for Eastern Europe (University of Leuven) given to A Omasta. M Van de Casteele is a Postdoctoral Fellow of FWO. We would like to thank J Van Pelt for advice and Glaxo-Wellcome for a grant in aid. A preliminary communication of the work was presented at the AASLD Meeting, $1996 .{ }^{19}$

\section{Authors' affiliations}

M Van de Casteelet, A Omastat, F Nevens, J Fevery, Laboratory of Hepatology, University Hospital Gasthuisberg, Leuven, B-3000 Leuven, Belgium

S Janssens, Laboratory of Experimental Cardiology, University Hospital Gasthuisberg, Leuven, B-3000 Leuven, Belgium

T Roskams, V Desmet, Laboratory of Histochemistry, University Hospital Gasthuisberg, Leuven, B-3000 Leuven, Belgium

†Both M Van de Casteele and A Omasta contributed equally to this work.

\section{REFERENCES}

1 Genecin P, Groszmann RJ. The biology of portal hypertension. In: Arias IM, Boyer JL, Fausto N, et al, eds. The liver: biology and pathobiology, 3rd edn. New York: Raven Press, 1994:1327-41.

2 Ryan J, Sudhir K, Jennings G, et al. Impaired reactivity of the peripheral vasculature to pressor agents in alcoholic cirrhosis. Gastroenterology 1993; 105: 1167-72.

3 Bosch J, Garcia-Pagan JC. Pathophysiology of portal hypertension and its complications. In: Bircher J, Benhamou JP, Mclntyre N, et al, eds. Oxford textbook of clinical hepatology. Oxford: Oxford University Press, 1999:653-60.

4 Bomzon A, Blendis LM. The nitric oxide hypothesis and the hyperdynamic circulation in cirrhosis. Hepatology 1994;20:1343-50.

5 Niederberger M, Martin PY, Ginès P, et al. Normalization of nitric oxide production corrects arterial vasodilatation and hyperdynamic circulation in cirrhotic rats. Gastroenterology 1995;109:1624-30.

6 Cahill PA, Redmond EM, Hodges R, et al. Increased endothelial nitric oxide synthase activity in the hyperemic vessels of portal hypertensive rats. J Hepatol 1996;25:370-8.

7 Bathal P, Grossman H. Reduction of the increased portal vascular resistance of the isolated cirrhotic rat liver by vasodilators. J Hepatol $1985 ; 1: 325-37$

8 Marteau $\mathbf{P}$, Ballet $F$, Chazouillères $O$, et al. Effect of vasodilators on hepatic microcirculation in cirrhosis. Hepatology 1989;9:820-3.

9 Reichen J, Le M. Verapamil favorably influences hepatic microvascular exchange and function in rats with cirrhosis of the liver. J Clin Invest 1986;78:448-55

10 Pinzani M. Novel insights into the biology and physiology of the lto cell. Pharmacol Ther 1995;66:387-412.

11 Rockey DC, Weisiger RA. Endothelin induced contractility of stellate cells from normal and cirrhotic rat liver: implications for regulation of portal pressure and resistance. Hepatology 1996;24:233-40.

12 Kawada N, Tran-Thi TA, Klein H, et al. The contraction of hepatic stellate (lto) cells stimulated with vasoactive substances; possible involvement of endothelin-1 and nitric oxide in the regulation of the sinusoidal tonus. Eur J Biochem 1993;213:815-23.

13 Zhang JX, Pegoli W, Clemens MG. Endothelin-1 induces direct constriction of hepatic sinusoids. Am J Physiol 1994;266:G624-32.

14 Rockey D. The cellular pathogenesis of portal hypertension: stellate cell contractility, endothelin and nitric oxide. Hepatology 1997;25:2-5.

15 Bataller R, Nicolas JM, Ginès $P$, et al. Arginine vasopressin induces contraction and stimulates growth of cultured human hepatic stellate cells. Gastroenterology 1997:113:615-24.

16 Shah V, Haddad FG, Garcia-Cardena G, et al. Liver sinusoidal endothelial cells are responsible for nitric oxide modulation of resistance in the hepatic sinusoids. J Clin Invest 1997;100:2923-30.

17 Mittal MK, Gupta TK, Lee FY, et al. Nitric oxide modulates hepatic vascular tone in normal rat liver. Am J Physiol 1994;267:G416-22.

18 Pannen BH, Baver M, Zhang JX et al. A time-dependent balance between endothelins and nitric oxide regulating portal resistance after endotoxin. Am J Physiol 1996;271:H1953-61.

19 Van de Casteele $\boldsymbol{M}$, Janssens S, Roskams T, et al. In vivo gene transfer of NO synthase reduces portal pressure in experimental cirrhosis in rats. Hepatology 1996;24:747A. 
20 Flück M, Van de Casteele M, Klossner W, et al. Sinusoidal but not prehepatic portal pressure is associated with decreased hepatic NO synthase activity. J Hepatol 1998;28:76.

21 Rockey DC, Chung JJ. Reduced NO production by endothelial cells in cirrhotic rat liver: endothelial dysfunction in portal hypertension. Gastroenterology 1998;114:344-51.

22 Gupta TK, Toruner M, Chung MK, et al. Endothelial dysfunction and decreased production of nitric oxide in the intrahepatic microcirculation of cirrhotic rats. Hepatology 1998;28:926-31.

23 Fischer-Nielsen A Poulsen HE, Hansen BA, et al. $\mathrm{CCl}_{4}$ cirrhosis in rats: irreversible histological changes and differentiated functional impairment. J Hepatol 1991;12:110-17.

24 Herz J, Gerard RD. Adenovirus-mediated transfer of low density lipoprotein receptor gene acutely accelerates cholesterol clearance in normal mice. Proc Natl Acad Sci U S A 1993:90:2812-16.

25 Janssens SP, Shimouchi A, Quertermous T, et al. Cloning and expression of a cDNA encoding human endothelium-derived relaxing factor/nitric oxide synthase. J Biol Chem 1992;267:14519-22.

26 Janssens SP, Bloch KD, Nong Z, et al. Adenoviral-mediated transfer of the human endothelial nitric oxide synthase gene reduces acute hypoxic pulmonary vasoconstriction in rats. J Clin Invest 1996;98:317-24.

27 Bradford MM. A rapid and sensitive method for the quantitation of microgram quantities of protein utilizing the principle of protein-dye binding. Anal Biochem 1976;72:248-54.

28 Laemmli UK. Cleavage of structural proteins during the assembly of the head of bacteriophage $T_{4}$. Nature 1970;227:680-5.

29 Sogni P, Moreau R, Lebrec D. Monoxyde d'azote, vasodilatation et cirrhose: un double (dés)equilibre. Gastroenterol Clin Biol 1999;23:101-4.

30 Rockey DC, Chung JJ. Regulation of inducible nitric oxide synthase in hepatic sinusoidal endothelial cells. Am J Physiol 1996;271:G260-7

31 Sarela AI, Mihaimeed FMA, Batten JJ, et al. Hepatic and splanchnic nitric oxide activity in patients with cirrhosis. Gut 1999;44:749-53.

32 Freeswick PD, Geller DA, Lancaster JR, et al. Nitric oxide and the liver. In: Arias IM, Boyer JL, Fausto N, et al, eds. The liver: biology and pathobiology, 3rd edn. New York: Raven Press, 1994:1031-45.

33 Bredt DS, Schmidt HHHW. The citrulline assay. In: Feelisch M, Stamler JS, eds. Methods in nitric oxide research. New York: John Wiley and Sons Ltd, 1996:249-55.

34 Ju H, Zou R, Venema VJ, et al. Direct interaction of endothelial nitric oxide synthase and caveolin-1 inhibits synthase activity. J Biol Chem 1997;272:18522-5.
35 Michel JB, Feron O, Sacks D, et al. Reciprocal regulation of endothelial nitric oxide synthase by Ca-calmodulin and caveolin. J Biol Chem 1997;272: 15583-6.

36 Shah V, Toruner M, Haddad F, et al. Impaired endothelial nitric oxide synthase activity associated with enhanced caveolin binding in experimental cirrhosis in the rat. Gastroenterology 1999;1 17:1222-8.

37 Roskams T, Van de Casteele M, Nevens F, et al. Different expression of NO synthase in human cirrhotic liver specimens may be related to different mechanisms of portal hypertension. Hepatology 1996;24:314A

38 Yu Q, Shao R, Qian HS, et al. Gene transfer of the neuronal NO synthase isoform to cirrhotic rat liver ameliorates portal hypertension. $J$ Clin Invest 2000;105:741-8.

39 Shah V, Chen AF, Cao S, et al. Gene transfer of recombinant endothelial nitric oxide synthase to liver in vivo and in vitro. Am J Physiol Gastrointest Liver Physiol 2000;279:G1023-30.

40 Van Roey G, Lijnen P, Verbesselt R, et al. Effect of narcotic agents and of bleeding on systemic and renal haemodynamics in healthy and $\mathrm{CCl} 4$ treated cirrhotic rats. Clin Sci 1997:93:549-56.

41 Li Q, Kay MA, Finegold $M$, et al. Assessment of recombinant adenoviral vectors for hepatic gene therapy. Hum Gene Ther 1993;4:403-9.

42 Ilan $Y$, Saito $H$, Thummala NR, et al. Adenovirus-mediated gene therapy of liver diseases. Semin Liver Dis 1999:19:49-59.

43 Huard J, Lochmüller $H$, Acsadi $G$, et al. The route of administration is a major determinant of the transduction efficiency of rat tissues by adenoviral recombinants. Gene Ther 1995;2:107-15.

44 Nakamura T, Akiyoshi H, Saito I, et al. Adenovirus-mediated gene expression in the septal cells of cirrhotic rat livers. J Hepatol 1999;30:101-6.

45 Rockey DC, Fouassier L, Chung JJ, et al. Cellular localization of endothelin-1 and increased production in liver injury in the rat: potential for autocrine and paracrine effects on stellate cells. Hepatology 1998;27:472-80

46 Weidenbach H, Nussler AK, Shu Z, et al. Nitric oxide formation lowers norepinephrine-induced intrahepatic resistance without major effects on the metabolism in the perfused rat liver. Hepatology 1997;26:147-54.

47 Van de Casteele M, Hösli M, Sägesser H, et al. Intraportal administration of glyceryl trinitrate or nitroprusside exerts more systemic than intrahepatic effects in anaesthetised cirrhotic rats. J Hepatol 1999;31:300-5. 